BISEI: Jurnal Bisnis dan Ekonomi Islam

Terakreditasi Nomor SK: B/4130/E5/.2.1/2019
Volume 06, Nomor 01, Juni 2021

E-ISSN 2541-2671. Hal. 1-12

\title{
Optimalisasi Investasi Dana Haji Melalui Sukuk dan Deposito Bank Syariah Terhadap Pengembangan Dana Haji Di Indonesia Periode 2016 - 2019
}

Tita Safitriawati ${ }^{1 *}$, Indar Fauziah Ulfah ${ }^{2}$, Neneng Widayati ${ }^{3}$

Program Studi Akuntansi, Fakultas Ekonomi dan Bisnis, Universitas Islam Syekh Yusuf

Jalan Maulana Hasanudin Tangerang, 42311, Indonesia

Abstract: Development of Hajj funds in Indonesia for the 2016-2019 period. This research uses a descriptive method by analyzing data taken from secondary data directly to the BPKH website and literature study. The data analysis technique used is data collection, data reduction, data display, verification, and concluding.

The results of this study indicate that the optimization of investment in hajj funds through Sukuk and Islamic bank deposits has increased from year to year so that it can increase financing in organizing Hajj. In 2018, referring to PP. 5 In 2018, BPKH plans to differentiate Hajj fund investments in gold (5\%), direct investment (15\%), and other investments (10\%).

Besides, the proportion of placement of funds in savings/time deposits decreased to $50 \%$ and placements in Sukuk to 20\%. Then, in 2020, the proportion of placement of funds in savings/time deposits will again decrease to only $30 \%$ and transfer this proportion to Sukuk and direct investment.

Keywords: Hajj, Sukuk, Deposito, Investment, BPKH

Paper type: Research Paper

*Corresponding author: tsafitriawati@unis.ac.id

Received: 08 April 2021, ; Accepted: 17 Juni 2021; Published: 25 Juni 2021

Cite this document: Safitriawati, Tita, dkk. (2021). Optimalisasi Dana Haji Melalui Sukuk dan Deposito Bank Syariah Terhadap Pengembangan Dana Haji di Indonesia Periode 2016-2019. BISEI: Jurnal Bisnis dan Ekonomi Islam, 6(1), 1-12.

Copyright (C) 2021, BISEI: Jurnal Bisnis dan Ekonomi Islam http://ejournal.unhasy.ac.id/index.php/bisei 
2 BISEI: Jurnal Bisnis dan Ekonomi Islam

Volume 06, Nomor 01, Juni 2021

\begin{abstract}
Abstrak: Tujuan Penelitian ini adalah untuk mengetahui optimalisasi investasi dana haji melalui sukuk dan deposito Bank syariah terhadap pengembangan dana haji di Indonesia periode 2016-2019. Penelitian ini menggunakan metode deskriftif dengan cara menganalisis data yang diambil dari data sekunder langsung ke website BPKH dan studi kepustakaan. Teknik analisis data yang digunakan yaitu dengan cara pengumpulan data, reduksi data, display data, verifikasi dan penarikan kesimpulan. Hasil penelitian ini menunjukkan bahwa optimalisasi investasi dana haji melalui sukuk dan deposito Bank syariah dari tahun ke tahun meningkat sehingga dapat menambah pembiayaan dalam penyelenggaraan haji. Pada tahu 2018, mengacu pada PP No. 5 Tahun 2018, BPKH merencanakan adanya diferensiasi investasi dana haji pada emas (5\%), investasi langsung (15\%), dan investasi lainnya (10\%). Selain itu, proporsi penempatan dana pada tabungan/deposito berkurang menjadi 50\% dan penempatan pada sukuk menjadi $20 \%$. Kemudian, pada tahun 2020, proporsi penempatan dana pada tabungan/deposito kembali berkurang menjadi hanya 30\% dan mengalihkan proporsi tersebut pada investasi sukuk dan investasi langsung
\end{abstract}

Kata kunci: Haji, Sukuk, Deposito, Investasi, dan BPKH

\title{
Pendahuluan
}

Haji adalah ibadah wajib bagi umat muslim yang mampu seperti yang terdapat dalam rukun islam yang ke lima. Ibadah haji dilakukan sesuai dengan waktu dan tempat prosesi yang sudah ditentukan yaitu hanya satu kali dalam setiap tahunnya. Kesempatan ibadah ini pada tanggal 9-13 dzulhijah yang bertempat di Arafah, Muzdalifah, Mina dan Makkah.

Dalam penyelenggaraan ibadah haji pemerintah menerapkan sistem kuota dengan mempertimbangkan jumlah penduduk muslim Indonesia di setiap provinsi dan penetapan kuota dari pemerintah Arab Saudi (Kementerian Agama, 2016). Pada tahun 2017 kuota haji di Indonesia ditetapkan menjadi 221.000 ribu jamaah. Jumlah tersebut didapatkan dari pemulihan kuota haji sebanyak 52.200 setelah pada tahun sebelumnya, yakni tahun 2016 jumlah kuota haji dipangkas menjadi 168.800 karena adanya kegiatan perluasan Masjidil Haram pada 2013-2016 (Kata data, 2017).

Ibadah haji setidaknya dilakukan sekali dalam seumur hidup, sehingga animo masyarakat Indonesia sangat besar untuk dapat melaksanakan ibadah tersebut. Tercatat hingga kini telah mencapai 4 juta muslim Indonesia terdaftar sebagai calon jama"ah haji. Besarnya animo masyarakat mengakibatkan akumulasi dana pendaftaran dana haji meningkat. (www.bpkh.com)

Menurut Undang-undang nomor 34 tahun 2016 tentang Pengelolaan Keuangan Haji, dana haji didefinisikan sebagai dana setoran biaya 
Tita Safitriawati, dkk: Optimalisasi Dana Haji Melalui Sukuk dan Deposito 3 Bank Syariah Terhadap Pengembangan Dana Haji di Indonesia Periode 2016-2019

penyelenggaraan ibadah haji, dan efisiensi penyelenggaraan haji dana ibadah umat. Undang-undang Keuangan haji juga mengandung amanah pembentukan Badan Pengelola Keuangan haji (BPKH). BPKH ini termasuk dalam lembaga pemerintah non struktural yang bertanggung jawab kepada Presiden melalui Menteri. Lembaga BPKH ini dilantik oleh Presiden pada tanggal 26 Juli 2016 diiringi dengan wacana tentang pemanfaatan potensi dana Haji guna membangun infrastruktur nasional dan subsidi produktif.

Selama ini dana haji dikelola dengan cara ditempatkan pada sektor-sektor perbankan. Ada tiga instrumen utama penempatan setoran awal Biaya Penyelenggara Ibadah haji (BPIH) yaitu dalam bentuk Surat Berharga Syariah nasional (Sukuk/SBSN), Surat utang negara (SUN), dan Deposito Berbasis Syariah.

Pengelolaan keuangan dana haji yang dilakukan oleh pemerintah salah satunya dengan penerbitan Surat Berharga Syariah Negara (SBSN) dalam hal ini produk Sukuk Dana Haji Indonesia (SDHI). Pemanfaatan keuangan haji ini telah sesuai dengan keputusan ijtima Ulama Komisi Fatwa Se-Indonesia IV Tahun 2012, bahwa setoran yang termasuk ke dalam daftar tunggu dalam rekening menteri agama boleh di Tasharruf-kan untuk hal-hal yang produktif (Memberikan Keuntungan) antara lain melalui penempatan di Perbankan Syariah atau diinvestasikan ke dalam bentuk sukuk (Primadhany, 2017).

Imbal hasil dari investasi dana haji yang saat ini dikelola oleh BPKH di tahun 2018 mencapai Rp. 6 Triliun, meningkat 28\% dibandingkan tahun 2017 sebesar Rp. 4,7 triliun. Nilai manfaat ini dialokasikan untuk penyelenggaraan ibadah haji dan operasonal BPKH. Sebesar 500 Milyar sudah terdistribusi kepada calon jemaah haji tunggu. Dan saat ini BPKH sudah mengembangkan layanan virtual account yang bisa digunakan calon jemaah haji untuk melihat perkembangan dananya melalui website BPKH di va.bpkh.go.id hal ini sejalan dengan mandat dari UUPKH (undang undang pengelolaan keuangan haji) sebagaimana tertuang dalam pasal 26 huruf c.(www.bpkh.com)

Tahun lalu di 2018 pengelolaan dana haji melebihi target BPKH, dari rencana awal ditargetkan 111,8 Triliun, Realisasinya mencapai 114 Triliun. Untuk tahun 2019 ini, dana haji sebesar 114 Triliun akan diinvestasikan secara langsung di bidang penerbangan dan katering, untuk penerbangan fokus di Indonesia bekerjasama dengan Garuda Indonesia, sementara di Arab Saudi fokus untuk investasi hotel dan katering. Dapat dipastikan oleh BPKH dana haji tidak ada satu sen pun untuk infrastruktur. Komposisi yang akan digunakan $50 \%$ di BPS BPIH (Bank penerima setoran Biaya Penyelenggaraan Ibadah Haji) dan 50\% di Investasi.

Berdasarkan uraian di atas penulis tertarik untuk meneliti sejauh mana optimalisasi investasi dana haji di Indonesia semenjak adanya institusi independen yaitu BPKH (Badan Pengelola Keuangan Haji) di Tahun 2017 lalu, dari segi investasi melalui sukuk yang sejak lama sudah dirilis yaitu SDHI (Sukuk Dana Haji Indonesia) dan juga deposito bank syariah. Maka penulis mengangkat Judul "Optimalisasi Investasi Dana Haji Melalui Sukuk dan deposito bank syariah terhadap Pengembangan Dana Haji Di Indonesia Periode 2016-2019" 


\section{Metode Penelitian}

Metode yang digunakan dalam penelitian ini adalah pendekatan kualitatif. Adapun yang dimaksud dengan penelitian kualitatif yaitu penelitian yang bermaksud untuk memahami fenomena tentang apa yang dialami oleh subjek penelitian secara holistik, dan dengan cara deskripsi dalam bentuk kata-kata dan bahasa, pada suatu konteks khusus yang alamiah dan dengan memanfaatkan berbagai metode ilmiah (Moleong, 2007:6).

Pendekatan penelitian ini adalah eksploratif deskriptif, dimana dalam konteks pengelolaan dana haji menggunakan Sukuk yang sudah lama digunakan sejak tahun 2001 baik SDHI maupun PBS infrastruktur dan investasi dalam bentuk deposito di Bank Syariah yang juga instrumen yang sudah lama digunakan. Selain itu, dengan pendekatan kualitatif diharapkan dapat diungkapkan situasi dan permasalahan yang dihadapi oleh BPKH dalam menjalankan peran investasi ini agar tetap menguntungkan dan meminimalisir resiko.

Teknik analisis data yang digunakan dalam penelitian ini adalah

1. Reduksi Data (Data Reduction)

Reduksi data, diartikan sebagai proses pemilihan, pemusatan perhatian pada penyederhanaan dan transformasi data kasar yang muncul dari catatan- catatan tertulis di lapangan. Reduksi dilakukan sejak pengumpulan data dimulai dengan membuat ringkasan, mengkode, menelusur tema, membuat gugus-gugus, menulis memo dan sebagainya dengan maksud menyisihkan data/informasi yang tidak relevan.

2. Display Data

Display data adalah pendeskripsian sekumpulan informasi tersusun yang memberikan kemungkinan adanya penarikan kesimpulan dan pengambilan tindakan. Penyajian data kualitatif disajikan dalam bentuk teks naratif. Penyajiannya juga dapat berbentuk matrik, diagram, tabel dan bagan.

3. Verifikasi dan Penegasan Kesimpulan (Conclution Drawing and Verification)

Merupakan kegiatan akhir dari analisis data. Penarikan kesimpulan berupa kegiatan interpretasi, yaitu menemukan makna data yang telah disajikan.

Antara display data dan penarikan kesimpulan terdapat aktivitas analisis data yang ada. Dalam pengertian ini analisis data kualitatif merupakan upaya berlanjut, berulang dan terus-menerus. Masalah reduksi data, penyajian data dan penarikan kesimpulan/ verifikasi menjadi gambaran keberhasilan secara berurutan sebagai rangkaian kegiatan analisis yang terkait.

Selanjutnya data yang telah dianalisis, dijelaskan dan dimaknai dalam bentuk kata-kata untuk mendiskripsikan fakta yang ada di lapangan, pemaknaan atau untuk menjawab 
Tita Safitriawati, dkk: Optimalisasi Dana Haji Melalui Sukuk dan Deposito 5 Bank Syariah Terhadap Pengembangan Dana Haji di Indonesia Periode 2016-2019

\section{Hasil dan Pembahasan}

\section{Konsep dasar Pengelolaan keuangan Haji}

Konsep dasar dalam pengelolaan Haji yaitu dengan adanya penerimaan dan pengeluaran sebagai berkut :

a. Sumber penerimaan :

1. Setoran awal

2. Setoran lunas

3. Nilai manfaat dari penempatan dana haji

4. Nilai manfaat dari investasi dana haji

5. Efisiensi dana operasional haji

6. Sumber lain (sah tidak mengikat

b. Item-item Pengeluaran :

1. Pengembalian kepada jamaah batal berangkat Haji

2. Penyelenggaraan ibadah Haji

3. Biaya Operasional BPKH

4. Virtual Account Jamaah Haji tunggu

5. Program kemaslahatan

Biaya yang harus dikeluarkan oleh jamaah haji tahun 2019 (jamaah reguler) :

Biaya haji per jamaah $(\mathrm{BPIH})=\mathrm{Rp} 67$ juta -76 juta
a. Setoran awal Rp 25 juta
b. Pelunasan Rp 8-15 juta
c. Nilai Manfaat BPKH Rp 35 juta

Dimana :
a. Jumlah hari $=42$ hari
b. Jamaah tunggu $=4,2$ juta
c. Waktu tunggu rata-rata $=20$ tahun
d. Kuota haji $=412$ ribu jamaah
e. Pendaftar $=650.000$ jamaah
f. Kontribusi / subsidi biaya haji dalam $\mathrm{BPIH}=50 \%$

\section{Pengelolaan Keuangan Dana Haji Pada Alokasi Investasi}

Dalam melakukan pengelolaan pada alokasi investasi telah diatur di UU No.34 Tahun 2014 pasal 48, sebagai berikut :

a. Penempatan dan investasi keuangan haji dapat dilakukan dalam bentuk produk perbankan, surat berharga,

b. emas, investasi langsung, dan investasi lainnya.

c. Penempatan dan investasi keuangan haji dilakukan sesuai dengan prinsip syariah dengan mempertimbangkan :

1) aspek keamanan, kehati-hatian, nilai manfaat, dan likuiditas.

2) Ketentuan lebih lanjut mengenai penempatan dan investasi keuangan haji diatur dalam peraturan pemerintah.

Setelah terbentuknya BPKH untuk investasi pada surat berharga dilakukan pada semua instrumen pasar modal syariah, yakni saham syariah, sukuk, reksadana syariah, dire, kik-eba, atau produk-produk capital market lainnya yang sesuai syariah termasuk deposito bank syariah. 
Berdasarkan data keuangan yang diperoleh dari BPKH tahun 2016 s.d 2019 sebagai berikut :

Tabel 1

Ringkasan Keuangan BPKH periode 2016-2019

(dalam Triliun Rupiah)

\begin{tabular}{|c|c|c|c|c|c|c|c|c|}
\hline Keterangan & 2016 & $\%$ & 2017 & $\%$ & 2018 & $\%$ & 2019 & $\%$ \\
\hline Dana kelolaan & 90,36 & 100 & 102,51 & 100 & 112,35 & 100 & 120,16 & 100 \\
\hline a.Investasi & 35,78 & 39,60 & 37,07 & 36,16 & 46,52 & 41,76 & 67,44 & 56,21 \\
\hline b.Deposito & 54,58 & 60,40 & 65,44 & 63,84 & 65,43 & 58,24 & 52,53 & 43,79 \\
\hline Nilai manfaat & \multicolumn{2}{|c|}{3,94} & \multicolumn{2}{|c|}{5,28} & \multicolumn{2}{|c|}{5,70} & \multicolumn{2}{|c|}{5,83} \\
\hline $\begin{array}{ll}\text { Alokasi Virtual } \\
\text { Account }\end{array}$ & & & & & \multicolumn{2}{|c|}{777 milyar } & \multicolumn{2}{|c|}{1,083 triliun } \\
\hline $\begin{array}{l}\text { Penyaluran } \\
\text { Program } \\
\text { kemaslahatan }\end{array}$ & & & & & \multicolumn{2}{|c|}{37 milyar } & \multicolumn{2}{|c|}{175,5 milyar } \\
\hline
\end{tabular}

Sumber : data yang diolah dari BPKH dan Kemenag

Berdasarkan data pada tabel 1 menunjukkan nilai investasi optimalisasi pengelolaan dana haji sebagai berikut :

1. Tren Pertumbuhan Dana Kelolaan Haji dan Nilai Manfaat

a. Tren Pertumbuhan Dana Kelolaan Haji

Tabel 2

Tren Pertumbuhan Dana Kelolaan Haji

\begin{tabular}{|c|c|c|}
\hline Tahun / keterangan & $\begin{array}{c}\text { Dana Kelola haji } \\
\text { (Triliun) }\end{array}$ & $\begin{array}{c}\text { Naik (Turun) } \\
(\%)\end{array}$ \\
\hline 2016 & 90,36 & - \\
\hline 2017 & 102,51 & 13,45 \\
\hline 2018 & 112,35 & 9,60 \\
\hline 2019 & 120,16 & 6,95 \\
\hline
\end{tabular}

Sumber : data diolah 2020

Berdasarkan tabel 2. di atas, terlihat dana kelolaan haji oleh BPKH mengalami pertumbuhan sejak periode tahun 2016 sampai dengan tahun 2019. Dana kelolaan haji yang diperoleh dari Kemenag tahun 2016 sebesar Rp. 90,36 triliun dan sejak dikelola oleh BPKH mulai tahun 2017 dana kelolaan haji meningkat signifikan menjadi Rp. 102,51 triliun atau sebesar 13.45\%. Dana kelolaan tersebut terus meningkat menjadi Rp. 112, 35 triliun pada tahun 2018, berikutnya pada tahun 2019 terus terjadi peningkatan dana kelolaan haji menjadi Rp. 120,16 triliun.

Copyright (C) 2021, BISEI: Jurnal Bisnis dan Ekonomi Islam http://ejournal.unhasy.ac.id/index.php/bisei 
Tita Safitriawati, dkk: Optimalisasi Dana Haji Melalui Sukuk dan Deposito 7 Bank Syariah Terhadap Pengembangan Dana Haji di Indonesia Periode 2016-2019

b. Tren Pertumbuhan Nilai Manfaat dari pengelolaan dana haji

Tabel 3

Tren Pertumbuhan Nilai Manfaat

\begin{tabular}{|c|c|c|}
\hline Tahun / keterangan & $\begin{array}{c}\text { Nilai Manfaat } \\
\text { (Triliun) }\end{array}$ & $\begin{array}{c}\text { Naik (Turun) } \\
(\%)\end{array}$ \\
\hline 2016 & 3,94 & - \\
\hline 2017 & 5,28 & 34,01 \\
\hline 2018 & 5,70 & 7,95 \\
\hline 2019 & 5,83 & 2,28 \\
\hline
\end{tabular}

Sumber : data diolah 2020

Berdasarkan tabel 4.2 yang menjelaskan pertumbuhan dana kelolaan haji, berikut disajikan dalam tabel 4.3 pertumbuhan nilai manfaat dari pengelolaan dana haji. Dari tabel 4.2 yang menggambarkan nilai pertumbuhan dana kelolaan haji, dan pada tabel 4.3 yang menggambarkan nilai manfaatnya maka terlihat tren pertumbuhan nilai manfaat tidak sebanding dengan pertumbuhan nilai dana kelolaan baik dari jumlah nilai (triliyun rupaih) maupun dalam persentase.

Berikut disajikan rincian nilai dana kelolaan per jenis instrumen investasi yang dilakukan oleh Kemenag dan BPKH pada sukuk dan deposito:

a. Investasi dalam sukuk

Tabel 4

Tren pertumbuhan investasi dalam Sukuk

\begin{tabular}{|c|c|c|}
\hline $\begin{array}{c}\text { Tahun / } \\
\text { keterangan }\end{array}$ & SUKUK (Triliun) & Naik/turun (\%) \\
\hline 2016 & 35,78 & - \\
\hline 2017 & 37,07 & 3,61 \\
\hline 2018 & 46,92 & 26,57 \\
\hline 2019 & 67,44 & 43,73 \\
\hline
\end{tabular}

Sumber : data diolah 2020

Dari tabel 4 di atas terlihat bahwa nilai dana kelolaan pada sukuk mengalami pertumbuhan yang signifikan sejak tahun 2016 sampai dengan tahun 2019. Pada tahun 2016 sewaktu masih dikelola Kemenag dana kelolaan pada sukuk sebesar Rp. 35,78 Triliun. Sejak pengelolaan dana haji diambil alih oleh BPKH pada tahun 2017 nilai investasi pada sukuk meningkat menjadi Rp. 37,07 triliun. Pada tahun 2018 nilai investasi pada sukuk terus mengalami peningkatan menjadi Rp. 46,92 triliun, serta pada tahun 2019 menjadi Rp. 67,44 triliun. 
b. Investasi dalam deposito

Tabel 5

Tren Pertumbuhan Investasi dalam Deposito

\begin{tabular}{|c|c|c|}
\hline Tahun / keterangan & Deposito (Triliun) & Naik / Turun (\%) \\
\hline 2016 & 54,58 & \\
\hline 2017 & 65,44 & 19,89 \\
\hline 2018 & 65,43 & $-0,02$ \\
\hline 2019 & 52,53 & $-19,72$ \\
\hline
\end{tabular}

Sumber : data diolah 2020

Dari tabel 5 terlihat nilai investasi dalam deposito mengalami fluktuasi apabila dibandungkan dengan nilai investasi pada sukuk yang menunjukkan tren pertumbuhan. Hal ini disebabkan nilai manfaat yang diperoleh dari nilai investasi yang berasal dari deposito tidak optimal apabila dibandingkan dengan nilai manfaat yang diperoleh dari investasi pada sukuk.

\section{Kontribusi nilai manfaat dari investasi sukuk dan deposito}

BPKH sebagai lembaga yang diberi amanah mengelola dana umat berupa dana haji, agar hasil invesasinya maksimal harus mempertimbangkan faktor manfaat dan resiko masing-masing instrumen investasinya. Ada 3 (tiga) cara penentuan portofolio optimal dengan metode Markowitz berdasarkan preferensi risiko investasi :

a. Pemilihan portofolio optimal berdasarkan nilai manfaat maksimal dengan resiko tinggi.

b. Pemilihan portofolio optimal berdasarkan nilai manfaat sebanding dengan risiko.

c. Pemilihan portofolio optimal berdasarkan nilai manfaat tanpa mau menerima resiko.

Berdasarkan data yang diperoleh darai Kemenag dan BPKH nilai manfaat (imbal hasil) dari total yang didapat dari investasi sukuk lebih besar dibandingkan dengan deposito karena bagi hasil atau tingkat pengembalian deposito lebih kecil,. Hingga tahun 2019, investasi surat berharga dilakukan oleh BPKH masih dalam bentuk Surat Berharga Syariah Negara (SBSN), atau yang biasa disebut Sukuk SDHI. Aspek keamanan dana Jamaah haji menjadi pertimbangan Investasi di SBSN. Sebab, Sukuk SDHI memiliki jaminan keamanan, pemerintah menjamin penempatan investasi di SBSN. Karena dijamin pemerintah, maka investasi di instrumen surat berharga atau sukuk SBSN itu tersebut dinilai aman. Selain memiliki risiko yang rendah karena di jamin oleh APBN, sukuk SDHI memiliki imbal hasil yang moderat, bahkan menguntungkan, termasuk pembayaran imbal hasil yang tepat waktu dan pengembalian pokok yangutuh. 
Tita Safitriawati, dkk: Optimalisasi Dana Haji Melalui Sukuk dan Deposito 9 Bank Syariah Terhadap Pengembangan Dana Haji di Indonesia Periode 2016-2019

\section{Strategi dalam pencapaian optimalisasi dan keberhasilan BPKH dalam mengoptimalisasi pengelolaan dana haji}

Strategi untuk mencapai target dan keberhasilan BPKH yaitu dengan dibuatnya Rencana Kerja Anggaran Tahunan (RKAT) diantaranya :

a. Strategi penempatan investasi ke dalam surat berharga, reksadana, sukuk, reksadana terproteksi.

b. Strategi pengajuan permohonan kepada kemenkeu terkait pengecualian pajak dalam penempatan dan investasi keuangan haji sebagaimana layaknya diberikan pada Lembaga Keuangan sejenis di Indonesia.

Hal ini dilaksanakan karena BPKH dituntut untuk dapat mengelola dana haji dalam rangka mendapatkan nilai manfaat yang optimal agar mampu mengantisipasi kekurangan pembiayaan haji tersebut. Salah satunya dengan instrumen surat berharga di pasar modal sebagai tempat untuk menginvestasikan dana haji yang dikelola oleh BPKH.

Luasnya ruang lingkup investasi ini menjadi tantangan tersendiri bagi $\mathrm{BPKH}$, terutama untuk menjalankan strategi investasi yang efektif dalam rangka mengoptimalkan nilai manfaatnya. Tantangan yang lain adalah bagaimana mengantisipasi kenaikan biaya pelaksanaan ibadah haji, baik yang langsung maupun yang tidak langsung, sehingga BPKH perlu menjalankan strategi investasi yang dapat memenuhi kebutuhan biaya tersebut melalui imbal hasil dari berbagai instrumen investasi.

Salah satu upaya yang dilakukan oleh BPKH untuk mengoptimalisasikan investasinya adalah mengurangi porsi alokasi penempatan dana haji di perbankan syariah secara perlahan dan memindahkannya ke instrumen investasi lain yang dianggap mampu memberikan imbal hasil yang lebih optimal. Jika sebelumnya penempatan dana haji di perbankan syariah mencapai 50 persen dari total dana kelola, maka tahun 2021 direncanakan penempatan tersebut cukup 30 persen. Sementara sisanya atau 70 persen akan dialokasikan ke berbagai instrumen investasi syariah yang sesuai peraturan yang dianggap mampu memberikan imbal hasil yang lebih optimal. Dari rencana investasi tersebut, BPKH mentargetkan mendapatkan sasaran nilai manfaat dana haji (gross) sebesar Rp10.5 triliun padatahun 2022

Dengan mempertimbangkan PP No. 5 Tahun 2018, BPKH telah menetapkan rencana penempatan dan investasi dana haji. Sebagai gambaran, pada tahun 2017, dana haji hanya ditempatkan pada dua instrumen investasi, yaitu tabungan/ deposito (65\%) dan Sukuk (35\%). Pada tahun 2018, mengacu pada PP No. 5 Tahun 2018, BPKH merencanakan adanya diferensiasi investasi dana haji pada emas (5\%), investasi langsung (15\%), dan investasi lainnya (10\%).

Selain itu, proporsi penempatan dana pada tabungan/deposito berkurang menjadi $50 \%$ dan penempatan pada sukuk menjadi $20 \%$. Kemudian, pada tahun 2020, proporsi penempatan dana pada tabungan/deposito kembali berkurang menjadi hanya $30 \%$ dan mengalihkan proporsi tersebut pada investasi sukuk dan investasi langsung. 


\section{Gambar 1 Penempatan dan Investasi Dana Haji}

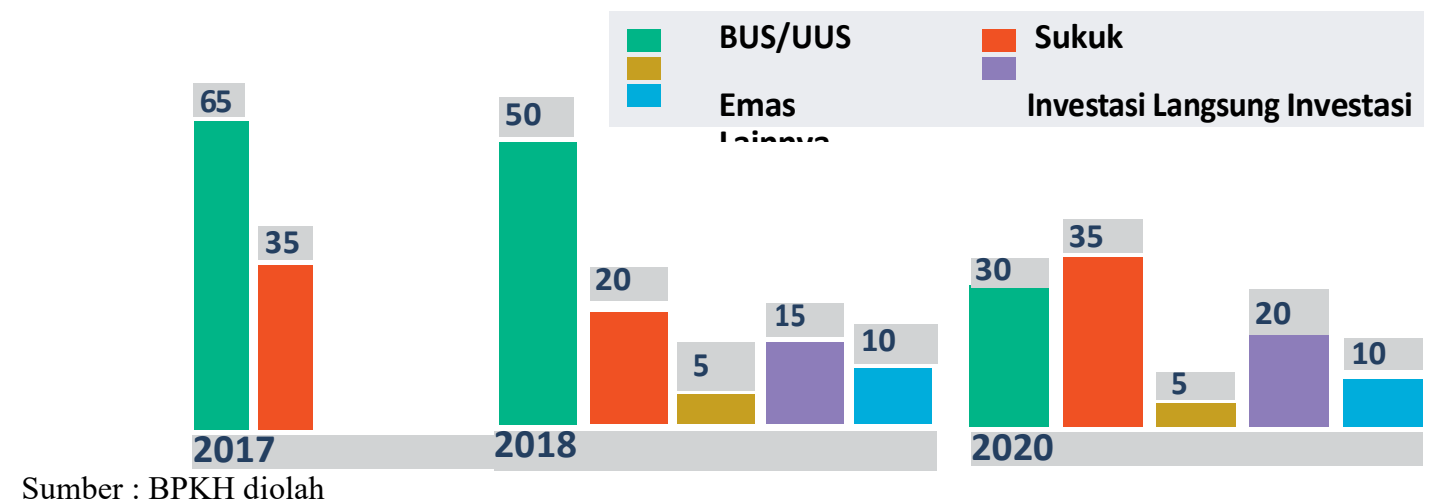

Supaya Nilai Manfaat lebih optimal, dengan parameter imbal hasil atau Yield dan hasil kelolaan keuangan haji dari kegiatan penempatan dan investasi yang dilakukan oleh BPKH. Dengan dasar UU 34 tahun 2014, pengelolaan oleh para profesional dan dukungan dari stakeholder, maka mandat $\mathrm{BPKH}$ adalah memberikan nilai manfaat yang optimal bagi Jamaah haji dan kemaslahatan umat. BPKH harus mampu memberikan imbal hasil atau Yield yang tinggi dengan mengalokasikan keuangan haji pada tingkat diatas ratarata namun tetap berisiko rendah. Porsi alokasi dana investasi untuk perbankan Syariah perlahan mulai dikurangi dan dipindahkan ke instrumen lainnya yang dianggap mampu memberikan imbal hasil yang lebih optimal. Dari rencana investasi tersebut, BPKH mentargetkan mendapatkan sasaran nilai manfaat dana haji (gross) sebesar Rp10.5 triliun pada tahun 2022.

Kepala BPKH, Anggito Abimanyu pada saat raker berharap bisa membawa seluruh stakeholders dan shareholders BPKH bersinergi mendukung investasi langsung. Untuk mendapatkan nilai manfaat yang optimum dibutuhkan sinergi dari berbagai lembaga terkait, untuk memitigasi risiko dan mempercepat proses investasi langsung.

\section{Penutup}

Berdasarkan pembahasan sebelumnya maka dapat ditarik kesimpulan sebagai berikut :

1. Pengelolaan dana haji yang sebelumnya dikelola oleh Ditjen Penyelenggaran Haji dan Umroh (PHU) Kementerian Agama, setelah pengelolaannya dilimpahkan ke BPKH hasilnya lebih optimal.

2. Dana haji yang sebelumnya hanya diinvestasikan pada tiga istrumen yakni Surat Berharga Syariah Nasional (SBSN), Surat Utang Negara (SUN) dan Deposito, setelah dikelola BPKH diversikfikasi investasinya lebih beragam.

3. BPKH dalam memilih instrumen investasi akan berusaha menghasilkan nilai manfaat yang paling optimal sehingga redistribusi kembali ke dana jamaah haji melalui virtual account masing - masing calon jemaah bisa maksimal sebagai bagian dari subsidi BPIH. 
Tita Safitriawati, dkk: Optimalisasi Dana Haji Melalui Sukuk dan Deposito 11 Bank Syariah Terhadap Pengembangan Dana Haji di Indonesia Periode 2016-2019

\section{Referensi}

Adiwarman Karim (2010), Bank Islam: Analisis Fiqh \& keuangan, Edisi 4 Grafindo Persada,Jakarta.

Ari haura .2010. "Pengelolaan Dana haji Pada Sukuk Dana Haji Indonesia (SDHI)". Skripsi Fakultas Syariah Dan Hukum UIN Syarif Hidayatullah Jakarta

Adi Ilham Akbar, "Aset”, Artikel diakses pada 29 Mei 2017 dari website http://investasipadaaset.

Alwi Rahman (2017), "Optimalisasi investasi dana biaya penyelenggaraan ibadah haji tahun 2016 oleh Ditjen Penyelenggaraan ibadah haji dan umroh Kementerian Agama Republik Indonesia, Skripsi, Program studi manajemen dan dakwah UIN Syarif Hidayatullah, Jakarta.

Datuk, B. (2014). Sukuk, Dimensi Baru Pembiayaan Pemerintah Untuk Pertumbuhan Ekonomi. Jurnal Riset Akuntansi dan Bisnis, 14(1).

Dusuki, A. W. (2010). Do equity-based Sukuk structures in Islamic capital markets manifest the objectives of Shariah??. Journal of Financial Services Marketing, 15(3), 203-214.

Hariyanto, E. (2017). Investasi Dana Haji pada Sukuk Infrastruktur. Website DJPPR Kementerian Keuangan, dilihat 11 Juli 2018, http://www.djppr.kemenkeu.go.id/page/load/1823.

Hotniar Siringringo (2005), Pemograman Linier: Seri Teknik Riset Operasi, (Yogyakarta: Graha Ilmu, )

Kasmir, Jakfar. 2012, “Studi Kelayakan Bisnis”. Jakarta: Kencana Prenada Media Grup

Mannan, Mohammad Abdul. (1996). Islamic Socioeconomic Institutions and Mobilization of Resources With Special Reference To Hajj Management Of Malaysia, Research Paper No. 40, Jeddah: Islamic Research and Training Institute-Islamic Development Bank. Mubarok, Jaih dan Hasanudin. (Januari 2013). Fatwa Tentang Pembiayaan Pengurusan Dana Haji dan Status Dana Calon Haji Daftar Tunggu, Jurnal Al-Iqtishad, Vol. V, No. 1.

Muhammad Zainul. 2016. "Analsiis Investasi Dana Haji Dalam Pembiayaan Infrastruktur dan peningkatan kualitas Penyelenggaraan Ibadah Haji”. Artikel Ilmiah Harmoni Edisi revisi 2016

Mohamad Wildan Abda'a. 2018. "Pemanfaatan Dana Haji Untuk Investasi (Tinjauan Undang-undang No. 34 Tahun 2014 Tentang Pengelolaan Keuangan Dana Haji Dan Perspektif Muslahah Mursalah”. Skripsi Fakultas Syariah Universitas Islam Negeri Maulna Malik Ibrahim Malang

Prastiwi, Devia Ambar 2013. "Pengaruh Indeks Harga Saham Gabungan (IHSG) dan Tingkat Suku Bunga Sertifikat Bank Indonesia (SBI) Terhadap Kinerja Reksadana yang Terdaftar di BEI Periode Januari 2007Desember 2011" Skripsi Fakultas Bisnis dan Manajemen Universitas Widyatama.

Peraturan Menteri Agama No. 34 Tahun 2014 tentang Sistem Pengelolaa Dana Haji. Pasal 1 diunduh dari http://Hajikemenag.go.id 
Suryomurti Wiku, Super Cerdas Investasi Syariah, (Jakarta: Qultum Media), Sugiyono (2017),Metode Penelitian Kuantitatif, Kualitatif, dan $R \& D$, Bandung Alfabeta, CV

Teguh dan Nur Diana (2019)," Analisis Manfaat dan Cost Penempatan Investasi Dana Haji pada Pembangunan Infrastruktur", Skripsi FEB Universitas Islam Malang

Tim Penyusun Kamus Pusat Pembinaan dan Pengembangan Bahasa, Kamus Besar Bahasa Indonesia pengertian Optimalisasi, (Balai Pustaka Jakarta, 1995)

www.bpkh.go.id

www.kemanag.go.id

https://www.bareksa.com/id/text/2017/07/28/setelah-sun-deposito-dana-hajiberpeluang-diinvestasikan-ke-infrastruktur/16141/news (diambil tanggal 19 Juli 2020 jam 10:13) 